Original Article

\title{
Pain syndromes in hemiplegic patients and their effects on rehabilitation results
}

\author{
Nil Sayiner Caglar ${ }^{1)}$, Turkan Akin ${ }^{1)}$, Ebru Aytekin ${ }^{1)}$, Ece Akyol Komut ${ }^{1)}$, \\ Fatma Ustabasioglu ${ }^{1)}$, SibelCaglar Okur $^{1)}$, YaseminPekin Dogan ${ }^{1)}$, Halil İbrahim Erdem ${ }^{1)}$, \\ Emine Ataoglu'), EbruYilmaz Yalcinkaya ${ }^{2)^{*}}$ \\ 1) Istanbul Training and Research Hospital, Physical Medicine and Rehabilitation Clinic, Turkey \\ 2) Istanbul Physical Medicine and Rehabilitation Training and Research Hospital, Physical Medicine \\ and Rehabilitation Clinic: Istanbul FTR Egitim ve Arastirma Hastanesi Adnan Kahveci Bulvarl \\ Bahcelievler, Istanbul 34180, Turkey
}

\begin{abstract}
Purpose] The aim of this study was to determine the frequency, type, and location of pain in hemiplegic patients and the effects on rehabilitation results in our inpatient rehabilitation unit. [Subjects and Methods] Patients rehabilitated between January 2010 and July 2012 were investigated retrospectively. Properties of pain were recorded. Pre- and post-rehabilitation motor evaluation and achievement in daily activities were considered, and differences in scores between groups classified as with and without pain were examined. [Results] The number of patients included in the study was 156 . The mean age was $64.28 \pm 12.45$ years, the mean disease duration was 11.10 months, and the gender distribution was 75 males (48\%) and 81 females (52\%). Fortysix (29.5\%) patients had pain complaints. The nociceptive pain ratio was $86.7 \%$, and the neuropathic pain ratio was $13.3 \%$. Pain was mostly localized at the shoulder joint, with the proportion being $86.9 \%$. In the pain group, statistically significant improvement was found in pain scores after the treatment. There was no significant difference between groups in the pre- and post-rehabilitation Brunnstrom motor evaluation and functional independence measurement scores. [Conclusion] Nociceptive pain is more common than neuropathic pain in patients with hemiplegia, and the shoulder joint is the most frequent location of nociceptive pain.

Key words: Pain, Stroke, Rehabilitation
\end{abstract}

(This article was submitted Jul. 21, 2015, and was accepted Nov. 25, 2015)

\section{INTRODUCTION}

Stroke is a major cause of morbidity and mortality in adult populations of developed countries. A substantial portion of those surviving from stroke will typically experience neurological sequelae and stroke-related complications. Pain is a common complication in patients with chronic stroke and may adversely affect patients' quality of life ${ }^{1-4)}$. Patients may develop various types of poststroke pain, with many causes playing a role in pain etiology. The most common type is nociceptive pain, in contrast, neurogenic pain, caused by a lesion affecting the spinothalamic pathways, is found in only $2-8 \%$ of patients ${ }^{5,6}$.

Decreasing the level of dependency in the performance of daily activities is generally the main objective of rehabilitation programs and other interventions for hemiplegic patients ${ }^{1)}$. The objective of stroke rehabilitation is to increase a patient's functional independence and maximize quality of life. Stroke rehabilitation uses stretching, strengthening, and joint range of motion exercises as well as facilitation techniques, biofeedback, electrical stimulation, and orthopedic devices to restore upper limb functions ${ }^{7}$.

The objective of this study was to determine the frequency and characteristics of pain in hemiplegic patients rehabilitated

\footnotetext{
*Corresponding author. EbruYilmazYalcinkaya (E-mail: ebru_yilmaz@hotmail.com)

C2016 The Society of Physical Therapy Science. Published by IPEC Inc.

This is an open-access article distributed under the terms of the Creative Commons Attribution Non-Commercial No Derivatives (by-nc-nd) License $<$ http://creativecommons.org/licenses/by-nc-nd/4.0/>.
} 
in our inpatient unit, and to compare their spasticity and motor assessment scores, as well as daily activity scores and functional ambulation scores, with those of hemiplegic patients without pain.

\section{SUBJECTS AND METHODS}

In this retrospective study, we investigated the records of 156 patients who had been diagnosed with stroke and admitted to our inpatient clinic to participate in a rehabilitation program. The approval of our institution's ethics committee was received. Each patient's age, gender, mean pain duration, etiological reason for stroke (hemorrhagic/ischemic), hemiplegic side (right/ left), presence of spasticity, duration of stroke (duration of disease), duration of hospitalization, and presence and duration of pain were recorded.

The rehabilitation physician evaluated spasticity according to the Ashworth scale and pain degree according to four point Likert pain scale. Motor assessment was done according to the Brunnstrom staging, daily activity skills were evaluated according to the Functional Independence Measure (FIM), and ambulation levels were assessed with Functional Ambulation Scale (FAS) ${ }^{1,8-13)}$.

The most common scale used for muscle tonus assessment is the 5-point Ashworth Scale. For better evaluation, the Modified Ashworth Scale (MAS) was developed by the addition of one grade $(+1)$ to the original Ashworth Scale ${ }^{8)}$. We use the MAS in our rehabilitation clinic.

Pain was evaluated with a four- point Likert scale: 0 , no pain; 1 , mild pain; 2 , moderate pain; and 3, severe pain ${ }^{14)}$.

The Brunnstrom motor staging test, which evaluates and interprets motion patterns according to the stage of motor function recovery, was used to evaluate the motor stages of patients at the time of hospitalization and discharge ${ }^{10,12)}$. For functional assessment, the FIM, which contains 2 parts in order to evaluate both motor and cognitive functions, is frequently used. Functional recovery was calculated as the difference between the FIM scores before and after the rehabilitation program ${ }^{9,11)}$.

The FAS shows the level of support needed for ambulatory patients and is valuable for determining the resumption of stepping and walking after a period of immobility. It is often used when a patient is admitted into our rehabilitation clinic. Patients were classified in to 6 categories, from 0 , indicating nonfunctional ambulation, through 5 , indicating an ambulatory patient (independent) ${ }^{13}$.

The localizations, causes, and types of pain in patients with pain complaints were obtained from medical records. These pain characteristics were determined with clinical and radiological examinations (magnetic resonance imaging and ultrasonography) as well as from information in the medical records. The LANSS (Leeds Assessment of Neuropathic Symptoms and Signs) pain scale was completed for patients having neuropathic pain ${ }^{15}$.

All patients were enrolled in a neurological rehabilitation program for 5 days a week according to their motor stage and FIM scale results. The treatment programs included Bobath and Brunnstrom techniques, therapeutic exercises (joint range of motion, muscle strengthening, passive stretching, and mobilization exercises), positioning, splinting, and walking training.

Based on the data in their records, those patients with musculoskeletal pain received medical treatment with analgesics (paracetamol 500-1200 mg/day), and nonsteroidal anti-inflammatory drugs (NSAIDs) (naproxen sodium $750 \mathrm{mg}$ and etodolac 400-600 mg daily), and patients with neuropathic pain received pregabalin (75-300 mg/day) or gabapentin (600-1,800 mg/ day). Physical therapy methods included transcutaneous electrical nerve stimulation (TENS), hot pack (HP), and ultrasound (US). Intra-articular injections were administered to patients those experiencing shoulder and knee joint problems. TENS was performed for 20 minutes at the site of pain with the conventional method (frequency 50-100, wavelength 100 microseconds, intensity 1-100 mA, and 20 sessions); US was performed on painful shoulders or knees $\left(1 \mathrm{Watt} / \mathrm{cm}^{2}\right.$ daily for a total of 20 sessions). Some patients were provided with shoulder braces, hand-wrist splints, ankle-foot orthoses, and forearm crutches if they were indicated. Suprascapular nerve block injections ( $3 \mathrm{cc}$ bupivacaine and $40 \mathrm{mg}$ triamcinolone) were performed with ultrasonographic imaging for 17 patients with shoulder pain on the hemiplegic side.

Based on the patients' records at admittance in to and discharge from our inpatient clinic, a statistical comparison of spasticity, Brunnstrom motor stages, and FIM and FAS scores was performed in both for the study group composed of patients who were experiencing pain and for the control group comprised of hemiplegic patients who had no pain. The mean hospitalization duration was 4 weeks.

Descriptive statistics were used for frequency calculations and determination of demographics. Clinical characteristics of hemiplegic patients with or without pain were compared by means of the Independent Samples t-test. Categorical data were compared using the $\chi^{2}$ test. The differences between Brunnstrom, FIM, and FAS scores were evaluated with the MannWhitney $U$ test and two-sided analysis of variance. For comparisons between the groups, $\mathrm{p}<0.05$ was considered statistically significant.

\section{RESULTS}

The recorded data of 156 patients were evaluated. The gender distribution was as 75 (48\%) males and $81(51.9 \%)$ females. The mean age was $64.28 \pm 12.45$ years, mean disease duration was 11.10 months (1-92), and mean duration of pain was 10.53 (0-84) months. Among the patients, 59 (37.8\%) had hemorrhagic cerebrovascular etiologies, and $97(62.2 \%)$ had ischemic cerebrovascular etiologies. Hemiplegia was on the right side in 116 patients $(74.4 \%)$ and on the left side in 40 
patients (25.6\%). Ten patients $(6.4 \%)$ had spasticity, and 46 patients $(29.5 \%)$ had pain complaints; $40(86.7 \%)$ of the patients with pain complaints complained of nociceptive pain, and the other $6(13.3 \%)$ complained of neuropathic pain (Table 1).

No statistically significant differences were found between patients with or without pain in terms of age, gender, hemiplegic side, spasticity, or FIM scores $(\mathrm{p}>0.05)$. The patients with left hemiplegia, however, had a higher rate of pain than those with right hemiplegia (Table 2).

Among patients with nociceptive pain, the most frequent location was in the shoulder joint for 38 patients $(64.40 \%)$, followed by the knee joint for 15 patients $(25.42 \%)$ (Table 3$)$.

In patients with shoulder pain, the etiologies of pain were determined to be adhesive capsulitis for 11 patients $(22.44 \%)$, rotator cuff tear and inflammation for another 11 patients (22.44\%), glenohumeral subluxation for 10 patients $(20.40 \%)$, and spasticity for 7 patients (14.28\%) (Table 4$)$.

Table 1. Patient demographics, kind of stroke, hemiplegic side, spasticity, and presence of pain

\begin{tabular}{|c|c|c|}
\hline \multicolumn{2}{|l|}{ Age (years) mean $\pm \mathrm{SD}$} & $64.28 \pm 12.45$ \\
\hline \multicolumn{2}{|c|}{ Duration of pain, mean (range) (months) } & $10.53(0-84)$ \\
\hline \multirow[t]{2}{*}{ Gender, n (\%) } & Male & $75(48.1)$ \\
\hline & Female & $81(51.9)$ \\
\hline \multirow[t]{2}{*}{ Kind of stroke, n (\%) } & Hemorrhagic & $59(37.8)$ \\
\hline & Ischemic & $97(62.2)$ \\
\hline \multirow[t]{2}{*}{ Hemiplegic side, $n(\%)$} & Right & $116(74.4)$ \\
\hline & Left & $40(25.6)$ \\
\hline \multirow[t]{2}{*}{ Spasticity, n (\%) } & Absence & $146(93.6)$ \\
\hline & Presence & $10(6.4)$ \\
\hline \multirow[t]{2}{*}{ Pain, n (\%) } & Nociceptive & $40(86.7)$ \\
\hline & Neuropathic & $6(13.3)$ \\
\hline
\end{tabular}

n: number of patients; SD: standard deviation

Table 2. Comparison of groups in terms of age, gender, hemiplegic side, spasticity, and FIM

\begin{tabular}{llcc}
\hline & & With pain & Without pain \\
\hline Age, $\mathrm{n}(\mathrm{mean} \pm \mathrm{SD})$ & & $46(65.3 \pm 11.4)$ & $110(63.8 \pm 12.8)$ \\
Gender, $\mathrm{n}(\%)$ & Male & $21(45.7 \%)$ & $54(49.1 \%)$ \\
& Female & $25(54.3 \%)$ & $56(50.9 \%)$ \\
Hemiplegic side, n (\%) & Right & $28(24.1 \%)$ & $88(75.9 \%)$ \\
& Left & $18(45.0 \%)$ & $22(55.0 \%)^{*}$ \\
Spasticity, n (\%) & Absence & $45(97.8 \%)$ & $101(91.8 \%)$ \\
& Presence & $1(2.2 \%)$ & $9(8.2 \%)$ \\
FIM & & $78.1 \pm 23.1$ & $72.5 \pm 23.9$ \\
\hline
\end{tabular}

FIM: Functional Independent Measure; n: number of patients; SD: standard deviation

$* \mathrm{p}<0.01$

Table 3. Localization of nociceptive pain

\begin{tabular}{lrr}
\hline Location & $\mathrm{n}$ & $\%$ \\
\hline Shoulder & 38 & 64.42 \\
Knee & 15 & 25.42 \\
Hip & 3 & 5.08 \\
Elbow & 3 & 5.08 \\
Neck & 1 & 1.69 \\
Arm soft tissue & 1 & 1.69 \\
\hline n: number of patients & &
\end{tabular}

Table 4. Causes of shoulder pain

\begin{tabular}{lrr}
\hline Causes of shoulder pain & $\mathrm{n}$ & $\%$ \\
\hline Adhesive capsulitis & 11 & 22.44 \\
Rotator cuff tear and tendinitis & 11 & 22.44 \\
Glenohumeral subluxation & 10 & 20.40 \\
Spasticity & 7 & 14.28 \\
Osteoarthritis & 3 & 6.12 \\
Bicipital tendinitis & 2 & 4.08 \\
Subacromial bursitis & 2 & 4.08 \\
Unknown etiology & 3 & 6.12 \\
\hline n: number of patients &
\end{tabular}


The mean pain scores evaluated before and after the treatment with the Likert scale were $1.75 \pm 0.72$ and $0.81 \pm 0.74$, respectively. In the group of patients who experienced pain, there was statistically significant improvement in pain level after the treatment $(\mathrm{p}<0.001)$. There was also a statistically significant improvement before and after therapy within the groups with or without pain according to the Brunnstrom recovery stages of the hand and lower extremity $(\mathrm{p}<0.01)$. There was no statistically significant difference between the patient groups with or without pain in terms of the Brunnstrom hand, upper limb, and lower limb recovery stages (Table 5).

There was statistically significant improvement before and after therapy within the groups with or without pain according to the FAS and FIM scores $(\mathrm{p}<0.001)$. No statistically significant difference was found between the two patient groups in terms of the FIM and FAS scores (Table 6).

\section{DISCUSSION}

In hemiplegic patients, musculoskeletal problems causing pain are frequently encountered. The presence of pain discourages patients from partipicating in rehabilitation programs and may interfere with improvement. If a patient cannot tolerate any activity or even passive shoulder motion because of pain, the efficacy of motor restoration techniques may decrease, and improvement may not be achieved. If hemiplegic shoulder pain is prevented or is treated effectively, it will not interfere with upper limb rehabilitation practices ${ }^{16)}$.

The mean age of the patients with pain ( $65 \pm 11.4$ years) was not statistically significantly different from the mean age of those without pain $(63.84 \pm 12.8$ years $)$. In contrast, Jonssan et al. reported that age was one of the most important factors that determine pain in stroke patients ${ }^{17}$. However another study, like ours, found no relationship between age and shoulder pain $^{18)}$.

No significant difference was detected in terms of gender in our patients with or without pain. A study by Myers et al. stated that men reported having less pain ${ }^{19}$. In our study, left hemiplegic patients had a higher rate of pain. A study conducted in 2012 reported that shoulder pain was more frequent in left hemiplegia. Neglect syndrome is more common in left hemiparesis. Because of this, it is possible that patients with neglect or sensory deficits have a tendency to avoid using their arms. Also, patients with neglect may have an increased risk for trauma of the shoulder and upper arm because of lack of proper care and positioning. It may be that poststroke pain is more common in patients with left hemiparesis because pain in the right side is unreported because of dysphasia and speech problems ${ }^{20)}$.

The tonus level of our patients was evaluated according to the Ashworth scale. No significant difference was found between the groups with or without pain. In the poststroke period, the rate of spasticity among our patients was $6.4 \%$. In

Table 5. Comparisons of Brunnstrom recovery stages of patients in groups with or without pain

\begin{tabular}{llll}
\hline & & With pain & \multicolumn{2}{c}{ Without pain } \\
& & $\mathrm{N}=46$ & 310 \\
\hline \multirow{2}{*}{ Hand } & Before rehabilitation & $3.0 \pm 2.0$ & $3.2 \pm 2.0$ \\
\multirow{2}{*}{ Upper extremity } & After rehabilitation & $3.4 \pm 2.0^{* *}$ & $3.6 \pm 1.9^{* *}$ \\
& Before rehabilitation & $2.8 \pm 1.7$ & $3.1 \pm 1.8$ \\
\multirow{2}{*}{ Lower extremity } & After rehabilitation & $3.3 \pm 1.6$ & $3.4 \pm 1.8$ \\
& Before rehabilitation & $3.7 \pm 1.5$ & $3.3 \pm 1.6$ \\
\hline
\end{tabular}

Data are presented as the mean $\pm \mathrm{SD}$.

$* * \mathrm{p}<0.01$ within groups

Table 6. Comparisons of FIM and FAS recovery stages of patients in groups with or without pain

\begin{tabular}{clcc}
\hline & & With pain & Without pain \\
& & $\mathrm{N}=46$ & $\mathrm{~N}=110$ \\
\hline \multirow{2}{*}{ FAS } & Before rehabilitation & $1.7 \pm 1.5$ & $1.5 \pm 1.8$ \\
& After rehabilitation & $2.4 \pm 1.5^{* *}$ & $1.9 \pm 1.7^{* *}$ \\
\multirow{2}{*}{ FIM } & Before rehabilitation & $78.1 \pm 23.1$ & $72.5 \pm 28.0$ \\
& After rehabilitation & $87.9 \pm 22.8^{* *}$ & $78.8 \pm 27.5^{* *}$ \\
\hline
\end{tabular}

n: number of patients; FAS: Functional ambulation scale; FIM: Functional Independence Measure

Data are presented as the mean $\pm \mathrm{SD}$.

$* * \mathrm{p}<0.001$ within groups 
another study, the rate of spasticity was $16 \%$ during the poststroke period. Spasticity holds the shoulder joint in the posture of flexion, adduction, and internal rotation, and aggravates shoulder problems ${ }^{21)}$.

Hemiplegic shoulder pain is one of the most common impairments after stroke, with prevalence rates varying from $6.9 \%$ to $26 \%{ }^{22)}$. In our study, 46 patients $(29.5 \%$ ) had pain complaints, of which $86.7 \%$ had nociceptive pain. In terms of pain localization, the most common pain location was found to be the shoulder joint $(86.9 \%)$. In other studies, the frequency of hemiplegic shoulder pain has been reported as $5 \%$ to $84 \%$ among hemiplegic patients ${ }^{16,23)}$.

Various clinical diagnoses such as rotator cuff tendinitis or tear, subacromial bursitis, bicipital tendinitis, adhesive capsulitis, brachial neuralgia, sympathetically mediated pain, and referred pain have been proposed as causes of hemiplegic shoulder pain syndrome ${ }^{24,25)}$. Among our patients suffering from shoulder pain, 11 (22.44\%) had adhesive capsulitis, $11(22.44 \%)$ had rotator cuff tear and tendinitis, 10 (20.40\%) had glenohumeral subluxation, 7 (14.28\%) had spasticity, $3(6.12 \%)$ had osteoarthritis, 2 (4.08\%) had bicipital tendinitis, and 2 (4.08\%) had subacromial bursitis.

The second major location of pain was the knee joint in $15(25.42 \%)$ of our patients. According to the literature, in the lower limbs of elderly subjects or patients with hemiplegia, the knee is most commonly the part of the body with arthritis. In patients with stroke, knee arthritis induces arthralgia, range of motion limitation, muscle strength reduction, and motor dysfunction $^{26)}$.

In our study, the rate of neuropathic pain was $13.3 \%$, and, after hemiplegic shoulder pain, it is the second most common painful condition in the literature, with the rate ranging from 2 to $8 \%{ }^{5,6}$. In another study, neuropathic pain was detected in $11 \%$ of the patients ${ }^{27}$.

We used LANSS for diagnosis of neuropathic pain. LANSS has high sensitivity and specificity for identifying neuropathic pain $^{28)}$. For detecting nociceptive pain, we used a Likert Scale. A recent study used Brief Pain Inventory Scale 12 and 23 for predicting shoulder pain in particular in stroke patients ${ }^{29}$.

Although a significant difference was found in Brunnstrom hand, upper limb, and lower limb recovery stages in hemiplegic patients with or without pain before and after rehabilitation, comparisons disclosed no statistical differences. Lindgren et al., studying shoulder pain in hemiplegic patients, found a relationship between shoulder pain prevalence and motor function. They reported that increased motor function was negatively related to shoulder pain prevalence ${ }^{20)}$.

We have observed that hemiplegic patients who had painful joints and were admitted to our clinic for rehabilitation were typically treated with injections and physical therapy modalities. In addition to this, statistically significant improvement was found in pain level after treatment in the group of patients who experienced pain. As with other types of neuropathic pain, physical therapy options (including massage, heat, and cold) may be used in combination with TENS ${ }^{30}$ ). Although a significant difference was found in Brunnstrom hand, upper limb, and lower limb recovery stages in hemiplegic patients with or without pain before and after rehabilitation, comparisons between the groups disclosed no statistically significant differences.

Hemiplegic shoulder pain limits daily activities of patients participating in neurological rehabilitation programs and aggravates functional results. Fernandez et al., in a review of the literature from various databases between 1980 and 2008 concluded that in hemiplegic patients with painful hemiplegic shoulder, Botulinum toxin injections combined with physical therapy decreased shoulder pain, whereas corticosteroid injections did not improve pain and range of motion ${ }^{31)}$. Electrical stimulation, on the other hand, was beneficial in reducing both shoulder pain and glenohumeral subluxation ${ }^{32,33)}$.

For poststroke shoulder pain, physiotherapy methods such as cold therapy, infrared treatment, ultrasound, and injections of intraarticular steroids and local analgesics are beneficial and recommended ${ }^{34,35)}$. For improvement of hemiplegic upper extremity pain and function, self-directed exercise with a task board was suggested in recent studies ${ }^{36}$.

No statistical difference was found between patient groups with or without pain in terms of FIM and FAS scores. A study by Yamamato et al. concluded that motor cortex stimulation administered to patients with stroke reduced pain; however, reduction of pain did not significantly correlate with motor recovery ${ }^{37)}$.

In conclusion, we found that nociceptive pain was more common than neuropathic pain in the patients with hemiplegia and that the shoulder joint was the most frequent location of nociceptive pain. Although statistically significant differences were found in pre- and post-rehabilitation motor, FIM, and FAS scores within each of the two groups in themselves, comparisons between these groups showed no statistical differences. The group of patients who experienced pain did not have worse functional scores than the pain-free patients, so we concluded that the presence of pain did not affect on the rehabilitation outcomes.

\section{REFERENCES}

1) Gialanella B, Santoro R, Ferlucci C: Predicting outcome after stroke: the role of basic activities of daily living predicting outcome after stroke. Eur J Phys Rehabil Med, 2013, 49: 629-637. [Medline]

2) Safer VB, Koseoglu BF: Timing of inpatient rehabilitation initiation in stroke patients: factors influencing early admission. J Phys Ther Sci, 2015, 27: 1913-1917. [Medline] [CrossRef]

3) Takemasa S, Nakagoshi R, Murakami M, et al.: Factors affecting quality of life of the homebound elderly hemiparetic stroke patients. J Phys Ther Sci, 2014, 26: 301-303. [Medline] [CrossRef] 
4) Shinohara T, Usuda S: Are contents of physical therapy in nine Japanese hospitals for inpatients with stroke related to inpatients' and physical therapists' characteristics? J Phys Ther Sci, 2013, 25: 641-647. [Medline] [CrossRef]

5) Leijon G, Boivie J, Johansson I: Central post-stroke pain—neurological symptoms and pain characteristics. Pain, 1989, 36: 13-25. [Medline] [CrossRef]

6) Andersen G, Vestergaard K, Ingeman-Nielsen M, et al.: Incidence of central post-stroke pain. Pain, 1995, 61: 187-193. [Medline] [CrossRef]

7) Kraft GH, Fitts SS, Hammond MC: Techniques to improve function of the arm and hand in chronic hemiplegia. Arch Phys Med Rehabil, 1992, 73: 220-227. [Medline]

8) Gregson JM, Leathley M, Moore AP, et al.: Reliability of the Tone Assessment Scale and the modified Ashworth scale as clinical tools for assessing poststroke spasticity. Arch Phys Med Rehabil, 1999, 80: 1013-1016. [Medline] [CrossRef]

9) Dodds TA, Martın DP, Stolov WC, et al.: A validation of the functional independence measurement and its performance among rehabilitation inpatients. Arch Phys Med Rehabil, 1993, 74: 531-536. [Medline] [CrossRef]

10) Hamzat TK, Olaleye OA, Akinwumi OB: Functional ability, community reintegration and participation restriction among community-dwelling female stroke survivors in Ibadan. Ethiop J Health Sci, 2014, 24: 43-48. [Medline] [CrossRef]

11) Linacre JM, Heinemann AW, Wright BD, et al.: The structure and stability of the Functional Independence Measure. Arch Phys Med Rehabil, 1994, 75: 127-132. [Medline]

12) Naghdi S, Ansari NN, Mansouri K, et al.: A neurophysiological and clinical study of Brunnstrom recovery stages in the upper limb following stroke. Brain Inj, 2010, 24: 1372-1378. [Medline] [CrossRef]

13) Holden MK, Gill KM, Magliozzi MR, et al.: Clinical gait assessment in the neurologically impaired. Reliability and meaningfulness. Phys Ther, 1984, 64: 35-40. [Medline]

14) Dogan SK, Ay S, Oztuna D, et al.: The utility of the Faces Pain Scale in the assessment of shoulder pain in Turkish stroke patients: its relation with quality of life and psychologic status. Int J Rehabil Res, 2010, 33: 363-367. [Medline] [CrossRef]

15) Yücel A, Senocak M, Kocasoy Orhan E, et al.: Results of the Leeds assessment of neuropathic symptoms and signs pain scale in Turkey: a validation study. J Pain, 2004, 5: 427-432. [Medline] [CrossRef]

16) Dromerick AW, Edwards DF, Kumar A: Hemiplegic shoulder pain syndrome: frequency and characteristics during inpatient stroke rehabilitation. Arch Phys Med Rehabil, 2008, 89: 1589-1593. [Medline] [CrossRef]

17) Jönsson AC, Lindgren I, Hallström B, et al.: Prevalence and intensity of pain after stroke: a population based study focusing on patients' perspectives. J Neurol Neurosurg Psychiatry, 2006, 77: 590-595. [Medline] [CrossRef]

18) Gamble GE, Barberan E, Laasch HU, et al.: Poststroke shoulder pain: a prospective study of the association and risk factors in 152 patients from a consecutive cohort of 205 patients presenting with stroke. Eur J Pain, 2002, 6: 467-474. [Medline] [CrossRef]

19) Myers CD, Riley JL 3rd, Robinson ME: Psychosocial contributions to sex-correlated differences in pain. Clin J Pain, 2003, 19: 225-232. [Medline] [CrossRef]

20) Lindgren I, Lexell J, Jönsson AC, et al.: Left-sided hemiparesis, pain frequency, and decreased passive shoulder range of abduction are predictors of long-lasting poststroke shoulder pain. PM R, 2012, 4: 561-568. [Medline] [CrossRef]

21) Turkel CC, Bowen B, Liu J, et al.: Pooled analysis of the safety of botulinum toxin type A in the treatment of poststroke spasticity. Arch Phys Med Rehabil, 2006, 87: 786-792. [Medline] [CrossRef]

22) Tao W, Fu Y, Hai-Xin S, et al.: The application of sonography in shoulder pain evaluation and injection treatment after stroke: a systematic review. J Phys Ther Sci, 2015, 27: 3007-3010. [Medline] [CrossRef]

23) Zhu Y, Su B, Li N, et al.: Pain management of hemiplegic shoulder pain post stroke in patients from Nanjing, China. Neural Regen Res, 2013, 8: 2389-2398. [Medline]

24) Braus DF, Krauss JK, Strobel J: The shoulder-hand syndrome after stroke: a prospective clinical trial. Ann Neurol, 1994, 36: 728-733. [Medline] [CrossRef]

25) Davis SW, Petrillo CR, Eichberg RD, et al.: Shoulder-hand syndrome in a hemiplegic population: a 5-year retrospective study. Arch Phys Med Rehabil, 1977, 58: 353-356. [Medline]

26) Lim KO, Lee DY, Shin WS: The effects of a warm whirlpool bath on pain and stiffness of patients with chronic stroke induced knee osteoarthritis. J Phys Ther Sci, 2013, 25: 873-875. [Medline] [CrossRef]

27) Bowsher D: Stroke and central poststroke pain in an elderly population. J Pain, 2001, 2: 258-261. [Medline] [CrossRef] 
28) Lee IH, Kim NY, Son CS, et al.: Clinical aspects of screening test tools for central neuropathic pain in patients with thalamic stroke. J Phys Ther Sci, 2011, 23: 749-752. [CrossRef]

29) An SH, Lee GC, Kim SY: A study of the clinical utility of the BPI-12 and 23 in predicting shoulder pain in stroke patients. J Phys Ther Sci, 2012, 24: 455-460. [CrossRef]

30) Ahmad M, Goucke CR: Management strategies for the treatment of neuropathic pain in the elderly. Drugs Aging, 2002, 19: 929-945. [Medline] [CrossRef]

31) Murie-Fernández M, Carmona Iragui M, Gnanakumar V, et al.: [Painful hemiplegic shoulder in stroke patients: causes and management]. Neurologia, 2012, 27: 234-244. [Medline]

32) Chan MK, Tong RK, Chung KY: Bilateral upper limb training with functional electric stimulation in patients with chronic stroke. Neurorehabil Neural Repair, 2009, 23: 357-365. [Medline] [CrossRef]

33) Price CI, Pandyan AD: Electrical stimulation for preventing and treating post-stroke shoulder pain: a systematic Cochrane review. Clin Rehabil, 2001, 15: 5-19. [Medline] [CrossRef]

34) Walsh K: Management of shoulder pain in patients with stroke. Postgrad Med J, 2001, 77: 645-649. [Medline] [CrossRef]

35) Yasar E, Vural D, Safaz I, et al.: Which treatment approach is better for hemiplegic shoulder pain in stroke patients: intra-articular steroid or suprascapular nerve block? A randomized controlled trial. Clin Rehabil, 2011, 25 : 60-68. [Medline] [CrossRef]

36) Lee HS, Kim JU: The effect of self-directed exercise using a task board on pain and function in the upper extremities of stroke patients. J Phys Ther Sci, 2013, 25: 963-967. [Medline] [CrossRef]

37) Yamamoto T, Katayama Y, Watanabe M, et al.: Changes in motor function induced by chronic motor cortex stimulation in post-stroke pain patients. Stereotact Funct Neurosurg, 2011, 89: 381-389. [Medline] [CrossRef] 